\title{
Erratum to: Early gastric cancer: virtual gastroscopy
}

\author{
J. H. Kim, ${ }^{1}$ H. W. Eun, ${ }^{2}$ S. S. Hong, ${ }^{1}$ Y. H. Auh ${ }^{3}$ \\ ${ }^{1}$ Department of Radiology, Soon Chun Hyang University Hospital, 657, Hannam-Dong, Yongsan-Ku, Seoul 140-743, Korea \\ ${ }^{2}$ Department of Diagnostic Radiology, College of Medicine, Ewha Womens University, Tongdaemun Hospital, \\ 70 Jongro 6 Street, Jongro-Ku, Seoul 110-126, Korea \\ ${ }^{3}$ Department of Radiology, Cornell University Weill Medical College, 520 East 70th Street, New York, New York, USA
}

\section{Erratum to: Abdom Imaging (2006) 31:507-513 DOI 10.1007/s00261-005-0183-1}

This article was inadvertently published a second time under DOI: 10.1007/s00261-006-9115-y. Official publication is under DOI: 10.1007/s00261-005-0183-1 in Abdom Imaging (2006) 31:507-513.

The online version of the original article can be found under doi:10.1007/s00261-005-0183-1.

Correspondence to: J. H. Kim; email: junghkim@hosp.sch.ac.kr 